\title{
On the Computation of Saturation Vapor Pressure ${ }^{1}$
}

\author{
F. W. Murray \\ The RAND Corporation, Sania Monica, Calif.
}

17 August 1966

In many meteorological applications it is necessary to compute the saturation vapor pressure of water. If changes in phase are to be considered, the saturation vapor pressure should be defined as the equilibrium vapor pressure under the existing environmental conditions of temperature and shape, size, and composition of adjacent matter (Huschke, 1959, p. 492). In practice it is virtually impossible to compute this quantity, but it is usually satisfactory to use instead the saturation vapor pressure over a plane surface of pure water or pure ice, which is a function of temperature only. Still another distinction can be made, namely, that between saturation vapor pressure of moist air and saturation vapor pressure in the pure phase. The former is meteorologically more significant, but the latter is easier to compute. In the meteorological range they differ by not more than 0.5 per cent (List, 1958, p. 347).

The internationally accepted formulation for saturation vapor pressure in the pure phase is that of Goff and Gratch (1946). For a plane surface of pure water the formulation is

$$
\begin{aligned}
\log _{10} e_{s w}= & -7.90298\left(\frac{T_{S}}{T}-1\right)+5.02808 \log _{10}\left(\frac{T_{S}}{T}\right) \\
& -1.3816 \times 10^{-7}\left(10^{\left.11.344\left[1-\left(T / T_{S}\right)\right]-1\right)}\right. \\
& +8.1328 \times 10^{-3}\left(10^{-3.49149\left[\left(T_{S} / T\right)-1\right]}-1\right) \\
& +\log _{10} e_{w s}
\end{aligned}
$$

where $T$ is the temperature $\left({ }^{\circ} \mathrm{K}\right), T_{S}=373.16 K$ and $e_{w s}=1013.246$ for vapor pressure in $\mathrm{mb}$.

For a plane surface of pure ice the formulation is

$$
\begin{array}{r}
\log _{10} e_{s i}=-9.09718\left(\frac{T_{0}}{T}-1\right)-3.56654 \log _{10}\left(\frac{T_{0}}{T}\right) \\
+0.876793\left(1-\frac{T}{T_{0}}\right)+\log _{10} e_{i 0}
\end{array}
$$

where $T_{0}=273.16 \mathrm{~K}$ and $e_{i 0}=6.1071$ for vapor pressure in $\mathrm{mb}$.

These forms are somewhat inconvenient for computation, but by simple operations they can be trans-

\footnotetext{
1 This work was supported by the Office of Naval Research under Contract Nonr-4715(00)(X) and was accomplished while the author was affiliated with Douglas Aircraft Company, Inc.
}

formed into

$$
\begin{aligned}
e_{s w}= & 7.95357242 \times 10^{10} \\
& \times \exp \left\{-18.1972839\left(\frac{T_{S}}{T}\right)+5.02808 \ln \left(\frac{T_{S}}{T}\right)\right. \\
& -70242.1852 \exp \left[\frac{-26.1205253}{\left(T_{S} / T\right)}\right] \\
& \left.+58.0691913 \exp \left[-8.03945282\left(\frac{T_{S}}{T}\right)\right]\right\},
\end{aligned}
$$

and

$$
\begin{aligned}
e_{s i}=5.75185606 \times & 10^{10} \exp \left\{-20.947031\left(\frac{T_{0}}{T}\right)\right. \\
& \left.-3.56654 \ln \left(\frac{T_{0}}{T}\right)-\frac{2.01889049}{\left(T_{0} / T\right)}\right\} .
\end{aligned}
$$

The constants in Eqs. (3) and (4) were derived by assuming the constants in Eqs. (1) and (2) to be exact and carrying as many significant digits as the capability of the computer permitted. Some values computed with the use of Eqs. (3) and (4) are given in Tables 1 and 2. The percentage difference of the logarithm of $e_{s w}$ computed by Eqs. (3) and (1) is at most $6 \times 10^{-5}$ per cent (at $-25 \mathrm{C}$ ), as compared with $2 \times 10^{-2}$ per cent uncertainty for Eq. (1) claimed by Goff and Gratch. The corresponding maximum difference between Eqs. (4) and (2) is $3 \times 10^{-5}$ per cent (at $-20 \mathrm{C}$ ), as compared with $3 \times 10^{-2}$ per cent uncertainty for $\mathrm{Eq}$. (2) claimed by Goff and Gratch. No claim was originally made for the validity of Eq. (1) below OC, but it has been adopted for use in that range for lack of any better formulation.

Although Eqs. (3) and (4) can readily be solved by means of a digital computer, for many applications a simpler relation is desirable. The equation most widely used by meteorologists is that of Magnus. As given by Tetens (1930) it is

$$
\log _{10} e=\frac{t u}{t+v}+w
$$


TABLE 1. Saturation vapor pressure over water.

\begin{tabular}{rccc}
\hline $\begin{array}{c}t \\
\left({ }^{\circ} \mathrm{C}\right)\end{array}$ & $\begin{array}{c}\text { Goff-Gratch } \\
(\mathrm{mb})\end{array}$ & $\begin{array}{c}\text { Tetens } \\
(\mathrm{mb})\end{array}$ & $\begin{array}{l}\text { Difference } \\
\text { (per cent) }\end{array}$ \\
\hline-50 & 0.06356 & 0.06078 & $-1.6 \times 10^{-2}$ \\
-45 & 0.1111 & 0.1074 & $-1.6 \times 10^{-2}$ \\
-40 & 0.1891 & 0.1842 & $-1.6 \times 10^{-2}$ \\
-35 & 0.3139 & 0.3078 & $-1.7 \times 10^{-2}$ \\
-30 & 0.5088 & 0.5018 & $-2.1 \times 10^{-2}$ \\
-25 & 0.8070 & 0.7993 & $-4.5 \times 10^{-2}$ \\
-20 & 1.2540 & 1.2462 & $2.8 \times 10^{-2}$ \\
-15 & 1.9118 & 1.9046 & $5.8 \times 10^{-3}$ \\
-10 & 2.8627 & 2.8571 & $1.9 \times 10^{-3}$ \\
-5 & 4.2149 & 4.2117 & $5.2 \times 10^{-4}$ \\
& & & \\
0 & 6.1078 & 6.1078 & $-1.8 \times 10^{-7}$ \\
5 & 8.7192 & 8.7227 & $-1.9 \times 10^{-4}$ \\
10 & 12.272 & 12.2789 & $-2.2 \times 10^{-4}$ \\
15 & 17.044 & 17.0523 & $-1.8 \times 10^{-4}$ \\
20 & 23.373 & 23.3809 & $-1.1 \times 10^{-4}$ \\
25 & 31.671 & 31.6749 & $-3.7 \times 10^{-5}$ \\
30 & 42.430 & 42.426 & $2.5 \times 10^{-5}$ \\
35 & 56.237 & 56.221 & $7.1 \times 10^{-5}$ \\
40 & 73.777 & 73.747 & $9.5 \times 10^{-5}$ \\
45 & 95.855 & 95.812 & $9.7 \times 10^{-5}$ \\
50 & 123.40 & 123.35 & $7.5 \times 10^{-5}$ \\
\hline & & & \\
\hline
\end{tabular}

where $t$ is the temperature $\left({ }^{\circ} \mathrm{C}\right), w=0.7858$ for vapor pressure in $\mathrm{mb}$, and

$$
\left.\left.\begin{array}{l}
u=9.5 \\
v=265.5
\end{array}\right\} \text { over ice; } \quad \begin{array}{l}
u=7.5 \\
v=237.3
\end{array}\right\} \text { over water. }
$$

Again a more convenient form is desired for routine computation, and Eq. (5) is easily transformed into

$$
e_{s}=6.1078 \exp \left[\frac{a(T-273.16)}{(T-b)}\right]
$$

where

$$
\left.\left.\begin{array}{l}
a=21.8745584 \\
b=7.66
\end{array}\right\} \text { over ice; } \begin{array}{l}
a=17.2693882 \\
b=35.86
\end{array}\right\} \text { over water. }
$$

These coefficients are related to those of Tetens by

$$
\begin{aligned}
& a=u \ln 10 \\
& b=273.16-v .
\end{aligned}
$$

As in the previous case $u$ was treated as exact in order to determine the value of $a$ with as many significant digits as the computer would permit. Thus, values computed from Eqs. (5) and (6) should be identical to that number of places.

Some values computed with the use of Eq. (6) are given in Tables 1 and 2. The last column of the tables gives the per cent difference between the logarithms of
TABLE 2. Saturation vapor pressure over ice.

\begin{tabular}{cccc}
\hline $\begin{array}{c}t \\
\left({ }^{\circ} \mathrm{C}\right)\end{array}$ & $\begin{array}{c}\text { Goff-Gratch } \\
(\mathrm{mb})\end{array}$ & $\begin{array}{c}\text { Tetens } \\
(\mathrm{mb})\end{array}$ & $\begin{array}{c}\text { Difference } \\
\text { (per cent) }\end{array}$ \\
\hline-50 & 0.03935 & 0.03817 & $-9.4 \times 10^{-3}$ \\
-4.5 & 0.07198 & 0.07032 & $-8.8 \times 10^{-3}$ \\
-40 & 0.1283 & 0.1261 & $-8.5 \times 10^{-3}$ \\
-35 & 0.2233 & 0.2205 & $-8.5 \times 10^{-3}$ \\
-30 & 0.3798 & 0.3764 & $-9.2 \times 10^{-3}$ \\
-25 & 0.6323 & 0.6286 & $-1.3 \times 10^{-2}$ \\
-20 & 1.032 & 1.028 & $1.2 \times 10^{-1}$ \\
-15 & 1.652 & 1.648 & $4.1 \times 10^{-3}$ \\
-10 & 2.597 & 2.595 & $9.9 \times 10^{-4}$ \\
-5 & 4.015 & 4.014 & $1.7 \times 10^{-4}$ \\
& & & \\
0 & 6.107 & 6.108 & $-6.3 \times 10^{-5}$ \\
\hline
\end{tabular}

the Goff-Gratch and Tetens saturated vapor pressures. This is defined as

$$
d=100\left[\frac{\ln e_{G}-\ln e_{T}}{\ln e_{G}}\right]
$$

where $e_{G}$ is determined from Eq. (3) or (4) and $e_{T}$ from $\mathrm{Eq}$. (6). Almost everywhere this difference is less than the uncertainty inherent in the Goff-Gratch formulation itself, which is $2 \times 10^{-4}$ per cent for Table 1 and $3 \times 10^{-4}$ per cent for Table 2 . The greatest difference between the two formulations occurs near -20 or $-25 \mathrm{C}$.

The magnitude of the per cent difference of the saturation vapor pressures themselves, as distinguished from their logarithms, increases with decreasing temperature, reaching 4.4 per cent at $-50 \mathrm{C}$ for Table 1 and 3.0 per cent at $-50 \mathrm{C}$ for Table 2 . For saturation over water it is less than 1 per cent for temperatures not below $-25 \mathrm{C}$ and less than 0.1 per cent for temperatures not below $-5 \mathrm{C}$. For saturation over ice the corresponding temperatures are -30 and $-10 \mathrm{C}$, respectively.

Hence, it is concluded that the Tetens formulation given by Eq. (6) is acceptable for most meteorological purposes. Only when extreme accuracy at low temperatures is required is it necessary to resort to the GoffGratch formulation.

\section{REFERENCES}

Goff, J. A., and S. Gratch, 1946: Low-pressure properties of water from -160 to 212 F. Trans. Amer. Soc. Heat. Vent. Eng., 52, 95-121.

Huschke, R. E., 1959: Glossary of Meteorology. Boston, Amer. Meteor. Soc., $638 \mathrm{pp}$.

List, R. J., 1958: Smithsonian Meteorological Tables (Sixth revised edition). Washington, D. C., The Smithsonian Institution, $527 \mathrm{pp}$.

Tetens, O., 1930: Ửber einige meteorologische Begriffe. $Z$. Geophys., 6, 297-309. 